\title{
Article \\ Microstructure and Thermal Deformation Behavior of Hot-Pressing Sintered Zr-6Al-0.1B Alloy
}

\author{
Huajun Yan ${ }^{1,2}$, Wei Wang ${ }^{1,2, *}$, Shuangjie Zhang ${ }^{1,3, *}$, Shibo Ma ${ }^{1, *}$, Jianhui Li ${ }^{1,2}$ and Bo Wang ${ }^{2}$ \\ 1 Hebei Key Laboratory of Material Near-Net Forming Technology, Hebei University of Science and Technology, \\ Shijiazhuang 050018, China; yanhj22@163.com (H.Y.); lijianhui_97@163.com (J.L.) \\ 2 School of Materials Science and Engineering, Hebei University of Science and Technology, \\ Shijiazhuang 050018, China; wangweicaijia@hebust.edu.cn \\ 3 Automobile Stamping Die Engineering Research Center, Botou 062150, China \\ * Correspondence: 18631175658@163.com (W.W.); zsjzlili@163.com (S.Z.); mashibo1980@163.com (S.M.)
}

check for updates

Citation: Yan, H.; Wang, W.; Zhang,

S.; Ma, S.; Li, J.; Wang, B.

Microstructure and Thermal

Deformation Behavior of

Hot-Pressing Sintered Zr-6Al-0.1B

Alloy. Materials 2022, 15, 1816.

https://doi.org/10.3390/

ma15051816

Academic Editor: Leszek Adam

Dobrzański

Received: 5 February 2022

Accepted: 24 February 2022

Published: 28 February 2022

Publisher's Note: MDPI stays neutral with regard to jurisdictional claims in published maps and institutional affiliations.

Copyright: (C) 2022 by the authors. Licensee MDPI, Basel, Switzerland. This article is an open access article distributed under the terms and conditions of the Creative Commons Attribution (CC BY) license (https:// creativecommons.org/licenses/by/ $4.0 /)$.

\begin{abstract}
Zr}-6 \mathrm{Al}-0.1 \mathrm{~B}$ alloy rich in $\mathrm{Zr}_{3} \mathrm{Al}$ phase is prepared by hot-pressing sintering. The thermal deformation behavior of sintered $\mathrm{Zr}-6 \mathrm{Al}-0.1 \mathrm{~B}$ is analyzed by isothermal compression tests at deformation temperatures of 950,1050 , and $1150{ }^{\circ} \mathrm{C}$ with strain rates of $0.01,0.1$, and $1 \mathrm{~s}^{-1}$. The results indicate that at the early stage of thermal deformation, the stress increases rapidly with the increase of strain and then reaches the peak value. Subsequently, the stress decreases with the increase of strain under the softening effect. On the whole, the true stress-strain curve shifts to the high stress area with the increase of strain rate or the decrease of deformation temperature, so the sintered $\mathrm{Zr}-6 \mathrm{Al}-0.1 \mathrm{~B}$ alloy belongs to the temperature and strain rate sensitive material. For the microstructure evolution of sintered $\mathrm{Zr}-6 \mathrm{Al}-0.1 \mathrm{~B}$ during the isothermal compression, the high strain rate can improve the grain refinement. However, because sintered $\mathrm{Zr}-6 \mathrm{Al}-0.1 \mathrm{~B}$ is a low plastic material, too high strain rate will exceed the deformation capacity of the material, resulting in an increase in defects. The increase of deformation temperature also contributes to grain refinement, but when the temperature is too high, due to the decomposition of $\mathrm{Zr}_{3} \mathrm{Al}$ phase, the deformation coordination of the material decreases, leading to the increase of the probability of the occurrence of defects. This study verified the feasibility of hot-pressing sintering to prepare $\mathrm{Zr}-6 \mathrm{Al}-0.1 \mathrm{~B}$ alloy rich in $\mathrm{Zr}_{3} \mathrm{Al}$ phase and laid the foundation of "hot-pressing sintering + canning hot-extrusion" process of $\mathrm{Zr}-6 \mathrm{Al}-0.1 \mathrm{~B}$ alloy components.
\end{abstract}

Keywords: Zr-6Al-0.1B; hot-pressing sintering; microstructure; thermal deformation behavior

\section{Introduction}

The importance of lightweight, long life, and high reliability to spacecraft components is self-evident. Scholars are working to find more applicative alloy systems with excellent performance in special service environments such as alternating temperature fields, irradiation, and atomic oxygen erosion, so as to maximize the service life of spacecraft components. Currently, materials used by spacecraft components are mostly stainless steel and titanium alloy. However, the feedback of in-orbit use proves that the stainless steel cannot meet the requirements of lightweight, and the titanium alloy has lower hardness and wear resistance, and shorter service life.

Zirconium alloy has better corrosion resistance, creep resistance, and radio resistance, which makes it a potential material for spacecraft components [1-3]. Previous studies have revealed that $\mathrm{Al}$ in $\mathrm{Zr}-\mathrm{Al}$ alloy, as a stable element of $\alpha$ phase, increases the $\alpha-\beta$ phase transition temperature of $\mathrm{Zr}$, and then increases the strength of the alloy [4-6]. In addition, $\mathrm{Al}$ as a lightweight element, comprehensively optimizes the strength and lightweight properties of the $\mathrm{Zr}-\mathrm{Al}$ alloy, and the content of $\mathrm{Al}$ in the alloy ranges from 1.24 to 2.78 (at.\%), Zr-Al alloy can form short-range ordered structure, improve the strength and hardness, but also maintain the particularly important plasticity. Therefore, $\mathrm{Zr}-\mathrm{Al}$ alloy provides a new direction for the development of spacecraft structural materials $[7,8]$. 
The studies of $\mathrm{Zr}-\mathrm{Al}$ compounds have found that the $\mathrm{Zr}_{2} \mathrm{Al}$ phase has high hardness and almost no plasticity at room temperature. Conversely, the $\mathrm{Zr}_{3} \mathrm{Al}$ phase has a facecentered cubic structure, because of the large number of actuated slip systems and good isotropic properties, so it has excellent plasticity, and is more suitable as an ideal matrix phase for structural materials [9].

Li et al. [10,11] prepared $\mathrm{Zr}-\mathrm{Al}$ alloy by smelting method, the effects of aluminum content (6.0, 7.0, 8.0 at.\%), annealing temperature, and annealing time on the phase composition and mechanical properties of $\mathrm{Zr}-\mathrm{Al}$ alloy were analyzed. They found that there is no $\mathrm{Zr}_{3} \mathrm{Al}$ phase in the as-casting $\mathrm{Zr}$-Al alloy and almost no plasticity when the phase composition is $\mathrm{Zr}_{2} \mathrm{Al}+\alpha-\mathrm{Zr}$. The annealing process is an effective way to obtain $\mathrm{Zr}_{3} \mathrm{Al}$ $+\alpha$-Zr phases, and the alloy has certain plasticity when the phase composition is $\mathrm{Zr}_{3} \mathrm{Al}$ $+\alpha-\mathrm{Zr}$, and with the increase of $\mathrm{Al}$ content, the tensile strength and microhardness of $\mathrm{Zr}_{3} \mathrm{Al}$ based alloy increase, while the ductility decreases.

Tewari et al. [12] studied the microstructural evolution of $\mathrm{Zr}_{3} \mathrm{Al}$ upon long-time annealing treatments. The formation of various phases, temperature regime of their stability, chemical composition, and volume fraction of these phases during prolonged annealing were ascertained. The morphology and distribution of the $\mathrm{Zr}_{3} \mathrm{Al}$ phase have been explained on the basis of long-range diffusion as the rate-controlling step, and a pseudobinary phase diagram with varying niobium concentration was developed.

Ren et al. [13] determined the self-diffusion mechanism of $\mathrm{Zr}_{3} \mathrm{Al}$ by systematic firstprinciples calculations based on density functional theory. The formation energies of four intrinsic point defects were calculated and the relationship between concentration of different point defects and temperature was determined. The effect of defect types on the stability of the system was explored after analyzing the electronic density of different supercells.

Yuan et al. [14] investigated elastic and thermodynamic properties of the $\mathrm{L}_{2}$ type structure $\mathrm{Zr}_{3} \mathrm{Al}$ intermetallic compound under high pressure and temperature using ab initio plane-wave pseudopotential density functional theory (DFT) within the generalized gradient approximation (GGA). They found the elastic modulus and compressional and shear wave velocities are increasing monotonically with increasing pressure.

Arıkan [15] investigated the elastic, electronic, and phonon properties of the intermetallic compounds $\mathrm{Zr}_{3} \mathrm{Al}$ in the $\mathrm{L}_{2}$ structure by employing an ab initio pseudopotential method and a linear-response technique within a generalized gradient approximation (GGA) of the density-functional theory (DFT) scheme. The electronic band structures of $\mathrm{Zr}_{3} \mathrm{Al}$ show that at the Fermi level, a major part of the contribution comes from $\mathrm{Zr} 4 \mathrm{~d}$ (Sc 3d) states.

The above studies on $\mathrm{Zr}-\mathrm{Al}$ alloy show that $\mathrm{Zr}_{3} \mathrm{Al}$ has good comprehensive properties with great application potential. In addition, a large number of studies have shown that multiple alloying can further improve the comprehensive properties of $\mathrm{Zr}-\mathrm{Al}$ alloy. For example, the addition of Sc element can effectively improve the recrystallization resistance of $\mathrm{Zr}-\mathrm{Al}$ alloy, and it also can obviously improve the depletion zone of the precipitated phase of Zr-Al binary alloy, making the precipitated phase tend to be evenly distributed. First-principle calculations also confirm that adding Sc in $\mathrm{Zr}-\mathrm{Al}$ alloy can effectively inhibit the transformation of $\mathrm{Al}_{3} \mathrm{Zr}$ from metastable $\mathrm{L}_{2}$ phase to high temperature stable $\mathrm{DO}_{23}$ phase, thus maintaining the recrystallization resistance of the alloy $[16,17]$. The addition of Ti element can reduce the lattice mismatch, and then stabilize the metastable phase $\mathrm{L1}_{2}-\mathrm{Al}_{3} \mathrm{Zr}[18,19]$. Furthermore, the $\mathrm{Nb}$ element can improve the ductility when retained by the alloy up to the composition $\mathrm{Zr}_{3} \mathrm{Al}_{0.5} \mathrm{Nb}_{0.5}$ [20].

In the studies of the effect of adding elements, what appeals to us is the research by Li et al. [21]. They analyzed the effect of B element on the microstructure and mechanical properties of $\mathrm{Zr}_{3} \mathrm{Al}$-based alloy. The results show that $\mathrm{B}$ element can significantly refine the grain size of $\mathrm{Zr}_{3} \mathrm{Al}$-based alloy. The grain size of $\mathrm{Zr}_{3} \mathrm{Al}$-based alloy decreases from $500 \mu \mathrm{m}$ to $30 \mu \mathrm{m}$ with by adding 0.1 (wt.\%) B element. The reason why we are interested is that $\mathrm{B}$ element has an excellent grain refining effect, and B element has a lower cost and is more accessible. 
At present, the billet of $\mathrm{Zr}-\mathrm{Al}$ alloy is mainly made by smelting method, which is not only expensive, but also complicated, has low production efficiency and raw material utilization rate. In comparison, hot-pressing sintering is a more flexible preparation method for alloys and composites, with good formability and applicability [22]. Hot-pressing sintering has been successfully applied to the preparation of a variety of alloys and composites, such as, Nickel-based superalloy [23,24], AA6082-ZTA composites [25], Ti-Zr alloys [26], Al-Ti-Zr alloys [27], Ti35Zr28Nb [28], SiC / Al-Zn-Mg-Cu [29], (Ti,Zr)B2-(Zr,Ti)C [30], Zr$1.2 \mathrm{Sn} 1 \mathrm{Nb}-0.4 \mathrm{Fe}$, and $\mathrm{Zr}-1.2 \mathrm{Bi}-1 \mathrm{Nb}-0.4 \mathrm{Fe}$ [31], etc.

In view of the above background, $\mathrm{Zr}-6 \mathrm{Al}-0.1 \mathrm{~B}$ alloy rich in $\mathrm{Zr}_{3} \mathrm{Al}$ phase is prepared by hot-pressing sintering in this study. The microstructure of hot-pressing sintered $\mathrm{Zr}$ $6 \mathrm{Al}-0.1 \mathrm{~B}$ alloy is analyzed by OM and SEM microscopic imaging techniques. The thermal deformation behavior and microstructure evolution of hot-pressing sintered Zr-6Al-0.1B alloy are analyzed by isothermal compression tests. This study verified the feasibility of hot-pressing sintering to prepare $\mathrm{Zr}-6 \mathrm{Al}-0.1 \mathrm{~B}$ alloy rich in $\mathrm{Zr}_{3} \mathrm{Al}$ phase and laid the foundation of "hot-pressing sintering + canning hot-extrusion" process of Zr-6Al-0.1B alloy components.

\section{Materials and Methods}

\subsection{Preparation of Zr-6Al-0.1B Alloy}

The mixed powder of $93.9 \%$ pure zirconium powder (200 mesh) $+6 \%$ pure aluminum powder $(200$ mesh $)+0.1 \%$ aluminum boron alloy powder (providing boron element) is obtained through low energy ball milling using a planetary ball mill. The model of planetary ball mill is DECO-30L manufactured by Changsha Deke Instrument Equipment Co., Ltd. in Changsha, Hunan Province, China. First, the three kinds of powder are loaded into a stainless-steel ball mill tank, and several stainless-steel balls are added in ball mill ratio 1:1. Then high purity argon $(99.99 \%)$ is used to exclude the air in the tank to protect the powder from oxidation and ignition during ball milling [32,33]. The powder mixing time is $30 \mathrm{~min}$ at the mixing speed $100 \mathrm{r} / \mathrm{min}$. The macroscopic morphology and SEM image of the mixed powder after ball milling are shown in Figure 1.

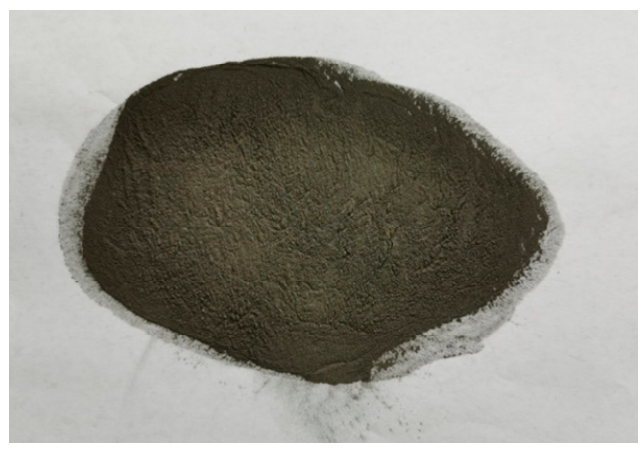

(a)

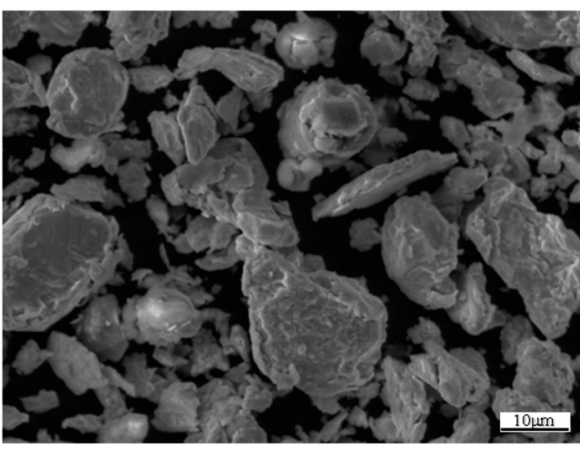

(b)

Figure 1. Mixed powder: (a) Macroscopic morphology of mixed powder; (b) SEM image of mixed powder.

Zr-6Al-0.1B alloy is prepared by vacuum hot-pressing sintering using the mixed powder. It should be pointed out that the hardness of $\mathrm{Zr}_{2} \mathrm{Al}$ phase is extremely high and there is almost no plasticity at room temperature. Rather, $\mathrm{Zr}_{3} \mathrm{Al}$ phase is a face-centered cubic structure with more slip systems, so it has good isotropy and more suitable plasticity for processing. Therefore, the key of vacuum hot-pressing sintering is to obtain $\mathrm{Zr}_{3} \mathrm{Al}$ phase, and the sintering temperature is a very crucial process parameter.

The hot-pressing sintering temperature should be ensured within the formation conditions of $\mathrm{Zr}_{3} \mathrm{Al}$, at the same time, it should be conducive to powder diffusion. According to the phase diagram of Zr-Al binary alloy as shown in Figure 2 [34], Zr has two allotropic crystals, $\alpha-\mathrm{Zr}$ with HCP crystal structure and $\beta-\mathrm{Zr}$ with BCC crystal structure, the phase 
transition temperature is $863^{\circ} \mathrm{C}$. As a stable element of $\alpha$ phase, $\mathrm{Al}$ can increase the phase transition temperature. When the mass fraction of $\mathrm{Al}$ is $6 \%$ (as shown in red dotted line in Figure 2), $\alpha-\mathrm{Zr}$ transform into $\beta-\mathrm{Zr}$ and the peritectic reaction " $\beta-\mathrm{Zr}+\mathrm{Zr}_{2} \mathrm{Al} \rightleftarrows \mathrm{Zr}_{3} \mathrm{Al}^{\prime}$ occurs when the temperature is higher than $910^{\circ} \mathrm{C}$. However, when the temperature is higher than $1019{ }^{\circ} \mathrm{C}$, the $\mathrm{Zr}_{3} \mathrm{Al}$ is decomposed into $\beta$ - $\mathrm{Zr}$ and $\mathrm{Zr}_{2} \mathrm{Al}$. In $\mathrm{Zr}-\mathrm{Al}$ alloy, boron element has little effect on phase transition temperature, and its main function is to retard grain growth and prevent oxidization. Therefore, the hot-pressing sintering temperature is selected as $950{ }^{\circ} \mathrm{C}$.

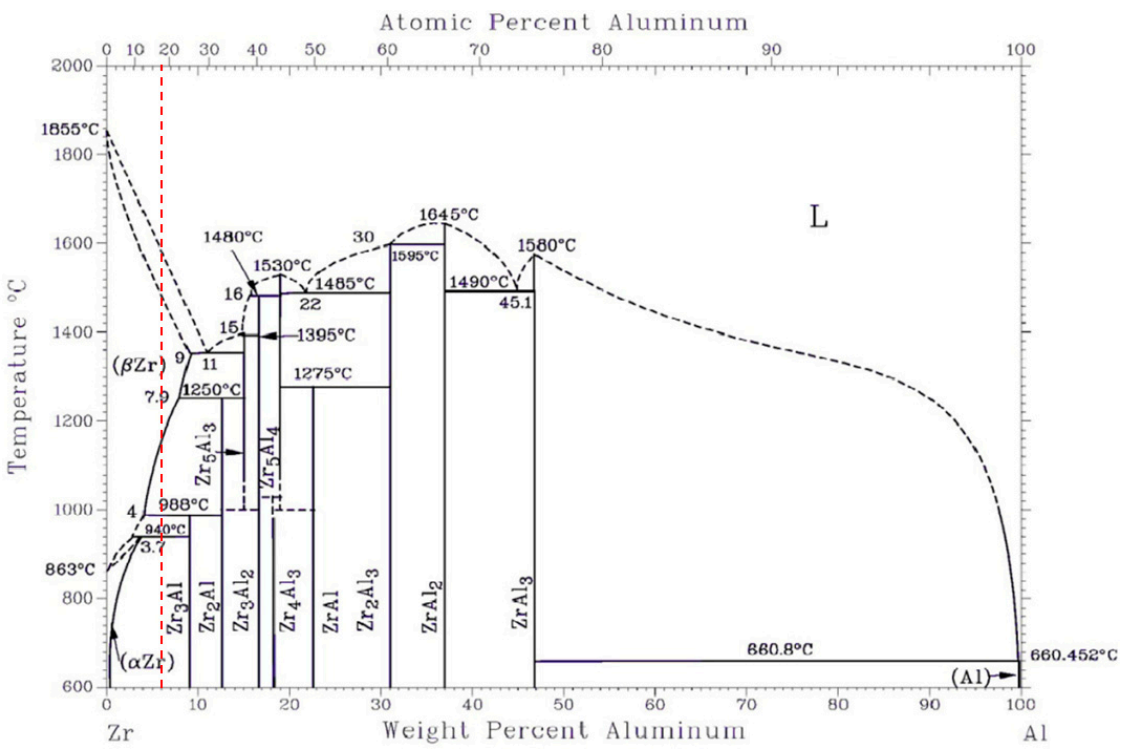

Figure 2. Phase diagram of Zr-Al binary alloy.

The vacuum hot-pressing sintering equipment is SMVB120/3 manufactured by Zhengzhou Golden Highway Co., Ltd. in Zhengzhou, Henan Province, China. Equipment parameters are as follows, the rated current of equipment is $182 \mathrm{~A}$, the maximum heating power is $120 \mathrm{~kW}$, the maximum sintering temperature is $1200^{\circ} \mathrm{C}$, the maximum compression force is $400 \mathrm{kN}$, the maximum sintering area (including mold) is $180 \mathrm{~cm}^{3}$, the maximum vacuum degree is $76 \mathrm{mmHg}$.

Graphite die is used for hot-pressing sintering, as shown in Figure 3. In order to prevent adhesion between metal powder and graphite die during hot-pressing sintering process, the surface of graphite die is evenly coated with a layer of boron nitride, and then mixed powder is loaded into the die, the fastening screw is tightened and put into the vacuum hot-pressing sintering furnace. In order to ensure the sintering effect, the bidirectional pressure mode is used to apply $15 \mathrm{MPa}$ pre-pressure on the graphite die. Then the furnace chamber pumped a vacuum. When the vacuum degree reaches $6 \times 10^{-2} \mathrm{~Pa}$, the die is heated to $500{ }^{\circ} \mathrm{C}$ at a rate of $10^{\circ} \mathrm{C} / \mathrm{s}$. Hold for $3 \mathrm{~min}$ to eliminate the temperature gradient and pressurize evenly at the same time. When the temperature rises to the specified hot-pressing sintering temperature $950{ }^{\circ} \mathrm{C}$, the pressure rises correspondingly to $40 \mathrm{MPa}$, and the holding time is $5 \mathrm{~min}$. Stop heating after the holding and pressure process. Stop pressurizing when the temperature drops to $500{ }^{\circ} \mathrm{C}$, and then the furnace body and the graphite die are cooled by the circulation water outside the furnace. 


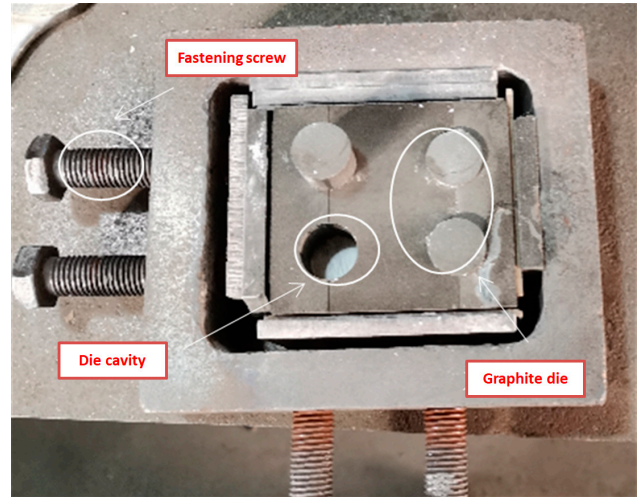

(a)

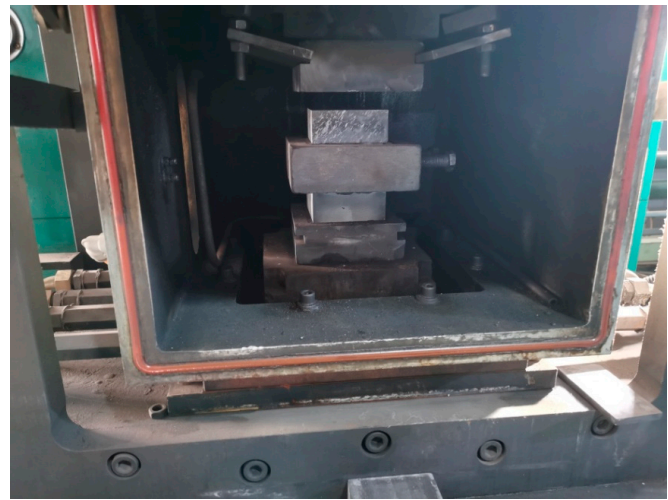

(b)

Figure 3. Graphite die and installation: (a) Graphite die; (b) Die Installation.

The sintered Zr-6Al-0.1B alloy workpieces are shown in Figure 4. The workpiece size is $\Phi 30 \mathrm{~mm} \times 20 \mathrm{~mm}$. It can be seen that there is no crack on the surface and the forming effect is good. The theoretical density of $\mathrm{Zr}-6 \mathrm{Al}-0.1 \mathrm{~B}$ is $5.98 \mathrm{~g} / \mathrm{cm}^{3}$, the actual density of the workpieces is $5.85 \mathrm{~g} / \mathrm{cm}^{3}$, the compactness reached $97.91 \%$, the hardness is 614.5 HV. The microstructure of the sintered Zr-6Al-0.1B alloy is observed by ZEISS Axio Vert.A1 optical microscope (OM) manufactured by Carl Zeiss in Oberkochen, Germany. And ZEISS ULTRA55 field emission scanning electron microscope (SEM) manufactured by Carl Zeiss in Oberkochen, Germany. The phase analysis is performed by D/MAX-2500 X-ray diffractometer (XRD) manufactured by Rigaku Japan Sales Division in Shibuya-ku, Tokyo, Japan. The distribution of alloying elements is detected by SEM-EDS.

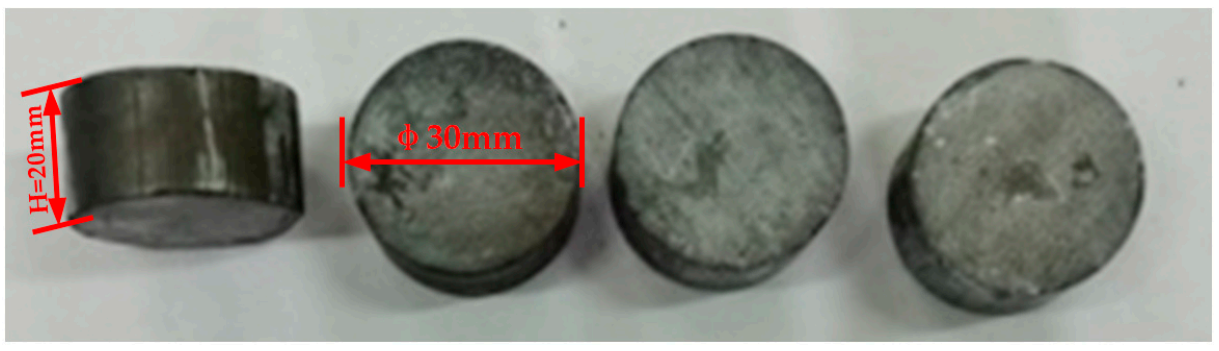

Figure 4. Sintered Zr-6Al-0.1B alloy workpieces.

\subsection{Isothermal Compression Tests}

The thermal deformation behavior of sintered Zr-6Al-0.1B alloy is analyzed by isothermal compression tests using a Gleeble-3500 thermal simulation machine manufactured by Data Sciences International, INC. in Delaware, USA. The isothermal compression samples with the size of $\Phi 6 \mathrm{~mm} \times 9 \mathrm{~mm}$ are cut by wire cutting from the sintered $\mathrm{Zr}-6 \mathrm{Al}-0.1 \mathrm{~B}$ alloy workpieces. Because $\mathrm{Zr}-6 \mathrm{Al}-0.1 \mathrm{~B}$ is a low plastic alloy, it is necessary to add steel capsule on the outer surface of the sample to prevent the sample from collapsing during isothermal compression, so as to obtain continuous stress-strain data. The addition of steel capsule is also compliance with the process design of "hot-pressing sintering + canning hot-extrusion".

The two end surfaces of the canned samples are covered with graphite flake to eliminate the effect of friction. The thermocouple is welded to the side wall of the samples to control the deformation temperature. The isothermal compression tests are carried out at deformation temperatures of 950,1050 , and $1150{ }^{\circ} \mathrm{C}$ with strain rates of $0.01,0.1$, and $1 \mathrm{~s}^{-1}$. Under vacuum condition, the sample is heated to the deformation temperature at a heating rate of $10{ }^{\circ} \mathrm{C} / \mathrm{s}$ and held for $30 \mathrm{~s}$ to eliminate the temperature gradient. The axial compression ratio is $50 \%$, i.e., the true strain reaches 0.69 . After the compression 
deformation, the specimen is quickly quenched into cold water to keep the microstructure. The samples after canning and isothermal compression are shown in Figure 5.

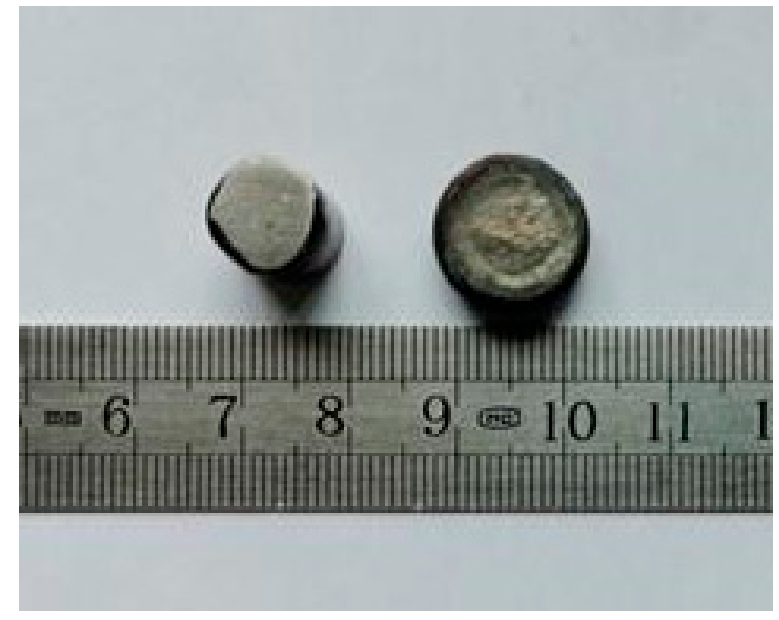

Figure 5. Samples after canning and isothermal compression.

To observe the microstructures of deformed specimens, they are sectioned parallel to the compression axis using wire cut electrical discharge machining (WEDM) and then the cut surface is polished. The microstructures are observed using ZEISS Axio Vert.A1 optical microscope (OM) and ZEISS ULTRA55 field emission scanning electron microscope (SEM) after etching with metallographic etchant $\left(5 \% \mathrm{HF}+15 \% \mathrm{HNO} 3+80 \% \mathrm{H}_{2} \mathrm{O}\right)$.

\section{Results and Discussion}

\subsection{Microstructure of Sintered Zr-6Al-0.1B Alloy}

The microstructures of sintered $\mathrm{Zr}-6 \mathrm{Al}-0.1 \mathrm{~B}$ alloy are shown in Figure 6. It can be seen from Figure $6 \mathrm{a}$ that the composed of microstructures are the light-colored $\mathrm{Zr}-\mathrm{Al}$ phase and dark-colored $\mathrm{Zr}$ phase, and the distribution is relatively uniform. The morphology of sintered $\mathrm{Zr}-\mathrm{Al}$ alloy is obviously different from that of melted $\mathrm{Zr}-\mathrm{Al}$ alloy $[9,21]$. The XRD result of the workpieces is shown in Figure 7. The results show that the microstructures are mainly composed of $\mathrm{Zr}_{3} \mathrm{Al}$ and $\alpha-\mathrm{Zr}$, indicating that under the above hot-pressing sintering conditions, the peritectic reaction " $\beta-\mathrm{Zr}+\mathrm{Zr}_{2} \mathrm{Al} \rightleftarrows \mathrm{Zr}_{3} \mathrm{Al}$ " is complete, the $\mathrm{Zr}_{2} \mathrm{Al}$ phase is fully transformed into $\mathrm{Zr}_{3} \mathrm{Al}$ phase, and the decomposition of $\mathrm{Zr}_{3} \mathrm{Al}$ phase does not occur.
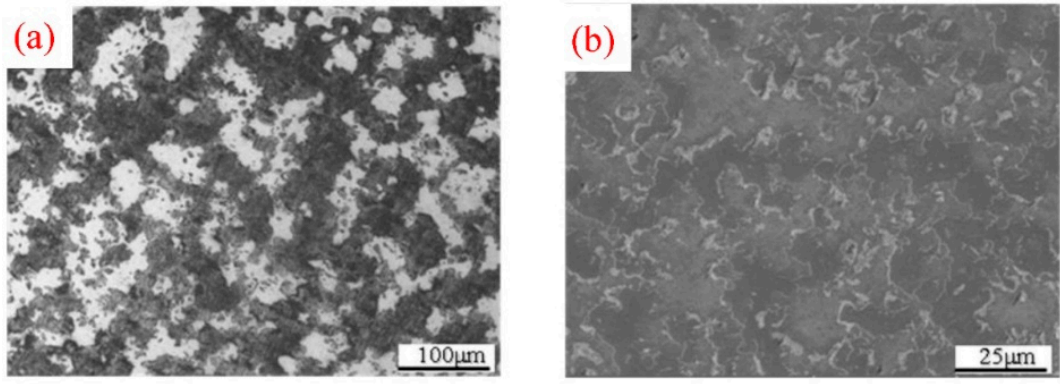

Figure 6. Microstructures of sintered Zr-6Al-0.1B alloy: (a) OM image; (b) SEM image. 


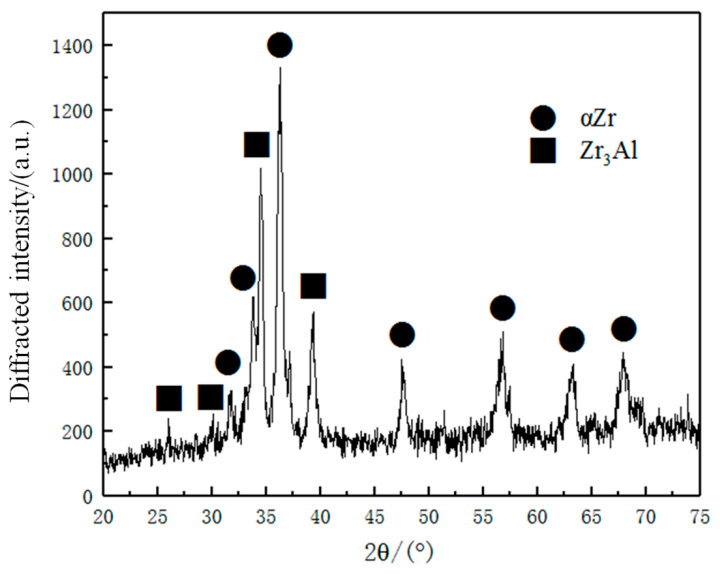

Figure 7. XRD result.

EDS analysis is carried out by SEM. The surface scanning results of alloying elements distribution are shown in Figure 8. The atomic percent of elements in regions P1 and P2 are listed in Table 1. The atomic ratios of $\mathrm{Zr} / \mathrm{Al}$ of the two regions are 16.59 and 3.19, respectively. It can be known that the $\mathrm{P} 1$ region is mainly $\mathrm{Zr}$, and the $\mathrm{P} 2$ region is mainly $\mathrm{Zr}-\mathrm{Al}$. It can be seen from Figure $8 \mathrm{~b}$ that the distribution of $\mathrm{Al}$ element corresponds to the $\mathrm{Zr}-\mathrm{Al}$ phase distribution, and slight segregation occurs along the grain boundary. As can be seen from Figure 8c, Zr elements are evenly distributed in the form of Zr matrix. As can be seen from Figure $8 d$, B element is distributed uniformly among alloying elements, but a trace amount of $\mathrm{B}$ element is also segregated along the grain boundary of $\mathrm{Zr}-\mathrm{Al}$ phase, indicating that part of B element is solid dissolved in this phase, which plays a role in reducing the alloy diffusion coefficient and hindering the grain growth of the alloy.

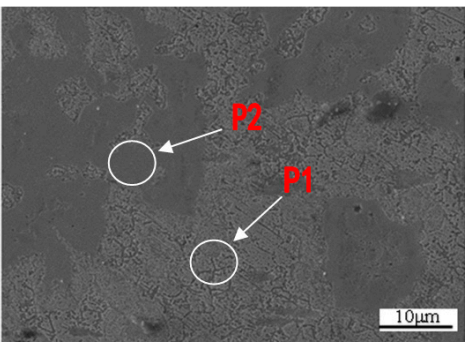

(a)

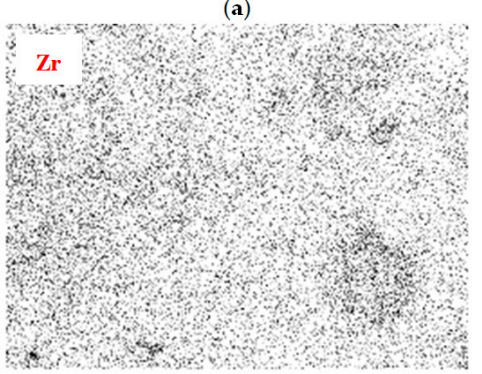

(c)

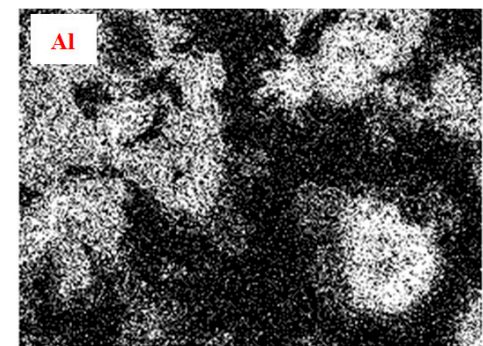

(b)

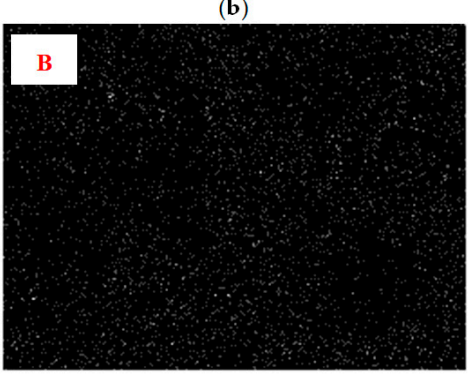

(d)

Figure 8. Scanning results of alloying elements: (a) Detection region; (b) Distribution of Al element; (c) Distribution of Zr element; (d) Distribution of B element.

Table 1. Atomic ratios of elements in regions P1 and P2 (at.\%).

\begin{tabular}{cccc}
\hline Region & Zr & Al & B \\
\hline P1 & 93.42 & 5.63 & 0.95 \\
P2 & 75.66 & 23.72 & 0.62 \\
\hline
\end{tabular}




\subsection{Thermal Deformation Behavior of Sintered Zr-6Al-0.1B Alloy}

The true stress-strain curves obtained by isothermal compression tests are shown in Figure 9. It can be seen that the variation trend of the true stress-strain curves under different deformation conditions is similar. At the early stage of thermal deformation, the stress increases rapidly with the increase of strain under the influence of work hardening and then reaches the peak value. Subsequently, the stress decreases with the increase of strain under the softening effect of dynamic recovery and dynamic recrystallization. On the whole, the true stress-strain curve shifts to the high stress area with the increase of strain rate or the decrease of deformation temperature, which belongs to the temperature and strain rate sensitive material, that is similar to that of sintered Ti-6Al-4V [35], SiC / AA6061 [36], Al2024TIN [37], and Fe-25Al-1.5Ta [38], but with a more pronounced softening phenomenon.
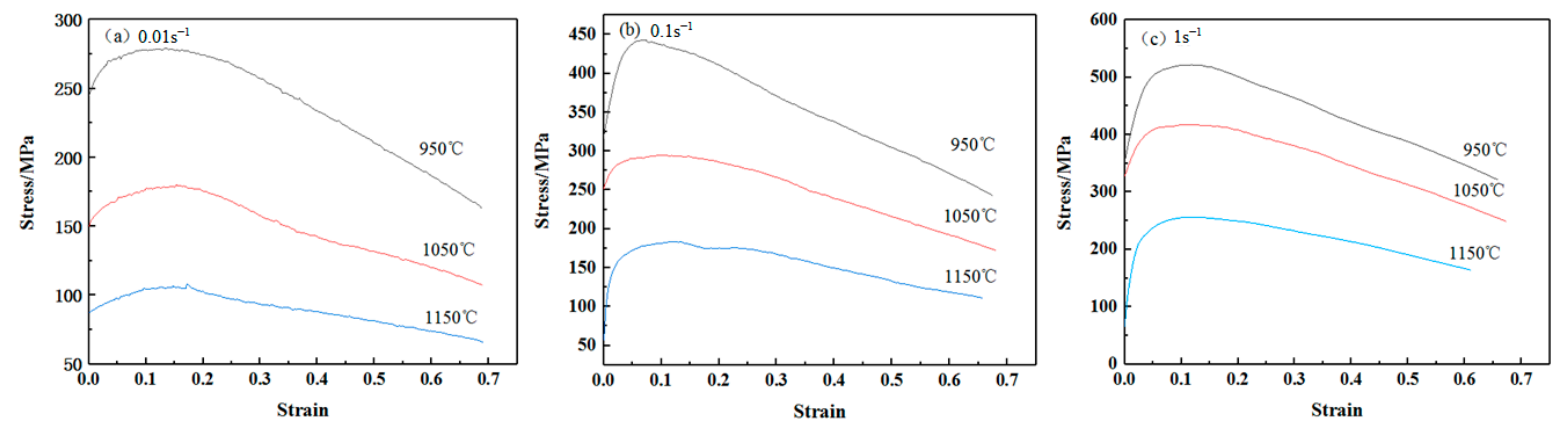

Figure 9. True stress-strain curves of sintered Zr-6Al-0.1B alloy: (a) strain rate of $0.01 \mathrm{~s}^{-1}$; (b) strain rate of $0.1 \mathrm{~s}^{-1}$; (c) strain rate of $1 \mathrm{~s}^{-1}$.

It should be pointed out that, due to a steel capsule being used to prevent the failure of the sintered samples during the isothermal compression tests, the obtained stress-strain curves describe the mechanical response of both steel capsule and sintered $\mathrm{Zr}-6 \mathrm{Al}-0.1 \mathrm{~B}$ alloy. It is impossible to separate the contribution of each material to the flow stress. For that reason, the thermal deformation behavior can only be analyzed qualitatively, but not quantitatively. It only provides a reference for the hot-working character of sintered Zr-6Al-0.1B alloy.

\subsection{Microstructure Evolution of Sintered Zr-6Al-0.1B Alloy}

The OM and SEM images of isothermal compression samples of Zr-6Al-0.1B alloy at $1050{ }^{\circ} \mathrm{C}$ under different strain rates are shown in Figure 10. As shown in Figure 10a,d, when the deformation rate is $0.01 \mathrm{~s}^{-1}$, most of the grains are unbroken with flat and slender form, and a few unclosed holes are distributed in the matrix. As shown in Figure 10b,e, when the deformation rate is $0.1 \mathrm{~s}^{-1}$, the microstructure of the alloy tends to be uniform, internal grain refinement has been improved, but there are obvious holes in the material. As shown in Figure 10c,f, when the deformation rate is $1 \mathrm{~s}^{-1}$, the microstructure of the alloy is more uniform and the grain refinement is the highest, but the porosity is obviously increased. 


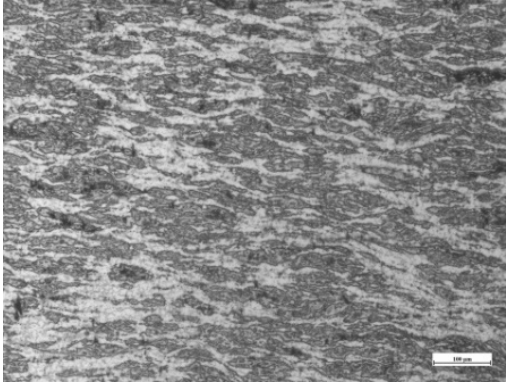

(a)

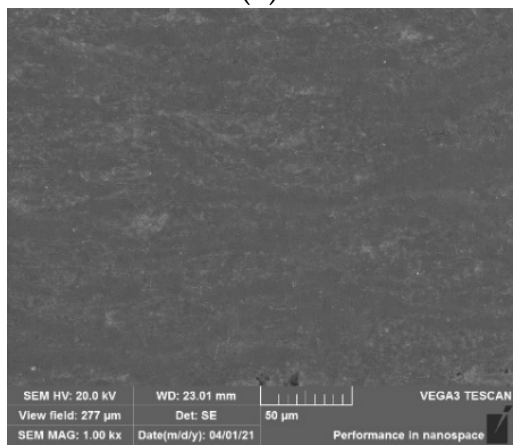

(d)

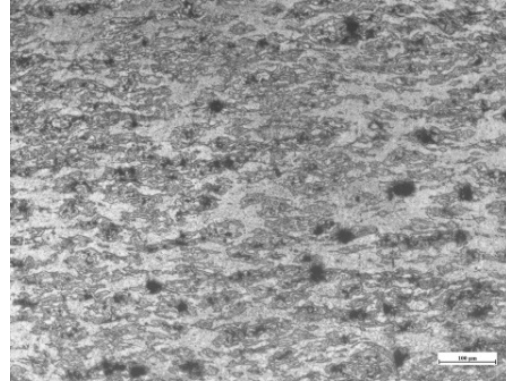

(b)

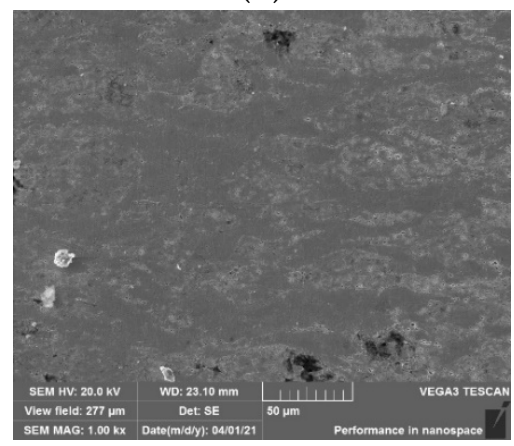

(e)

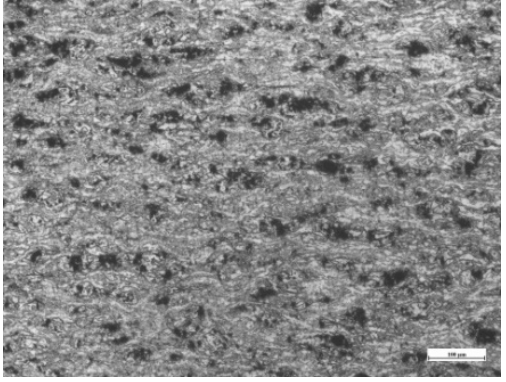

(c)

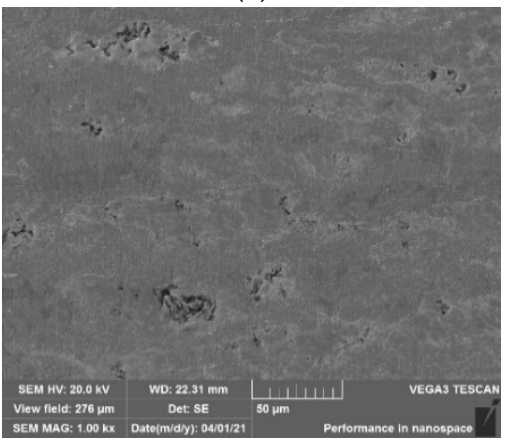

(f)

Figure 10. Microstructure of Zr-6Al-0.1B alloy at $1050{ }^{\circ} \mathrm{C}$ : (a) $\mathrm{OM}$ image of $0.01 \mathrm{~s}^{-1}$; (b) OM image of $0.1 \mathrm{~s}^{-1}$; (c) OM image of $1 \mathrm{~s}^{-1}$; (d) SEM image of $0.01 \mathrm{~s}^{-1}$; (e) SEM image of $0.1 \mathrm{~s}^{-1}$; (f) SEM image of $1 \mathrm{~s}^{-1}$.

On the whole, for sintered $\mathrm{Zr}-6 \mathrm{Al}-0.1 \mathrm{~B}$ alloy, the high deformation rate can provide a large recrystallization nuclear force, which is conducive to improving the grain refinement. However, because sintered $\mathrm{Zr}-6 \mathrm{Al}-0.1 \mathrm{~B}$ alloy is a low plastic material, a too high deformation rate will exceed the deformation capacity of the material, resulting in an increase in defects of hole. Through an overall consideration, it is suggested to adopt relatively high strain rate in the subsequent selection of plastic processing technology. It is necessary to adopt the processing technology with three compressive stress states, such as extrusion, to improve the degree of material microstructure refinement and inhibit the generation and expansion of holes [39-41].

The OM and SEM images of isothermal compression samples of Zr-6Al-0.1B alloy at $0.1 \mathrm{~s}^{-1}$ under different deformation temperatures are shown in Figure 11. As shown in Figure 11a,d, when the deformation temperature is $950{ }^{\circ} \mathrm{C}$, the deformation of the material is more uniform, the $\mathrm{Zr}$-Al phase can be evenly distributed, and the internal holes are relatively few. As shown in Figure 11b,e, when the deformation temperature is $1050{ }^{\circ} \mathrm{C}$, although the increase of deformation temperature promotes the migration of grain boundary and accelerates the dynamic recrystallization inside the material, the grain refinement degree is slightly improved. However, $\mathrm{Zr}$ and bright white $\mathrm{Zr}$ - $\mathrm{Al}$ phases are fibrous and have poor microstructure uniformity. As shown in Figure 11c,f, when the deformation temperature is $1150{ }^{\circ} \mathrm{C}$, dynamic recrystallization is more sufficient and grain size is more refined. However, a large number of obvious holes appear in the material, which is because at this temperature, $\mathrm{Zr}_{3} \mathrm{Al}$ phase with good plasticity is decomposed into $\mathrm{Zr}_{2} \mathrm{Al}$ phase with poor plasticity. There is a great difference between the plasticity of $\mathrm{Zr}_{2} \mathrm{Al}$ phase and $\mathrm{Zr}$ phase, so the deformation coordination of the material is reduced, leading to the generation of defects. 


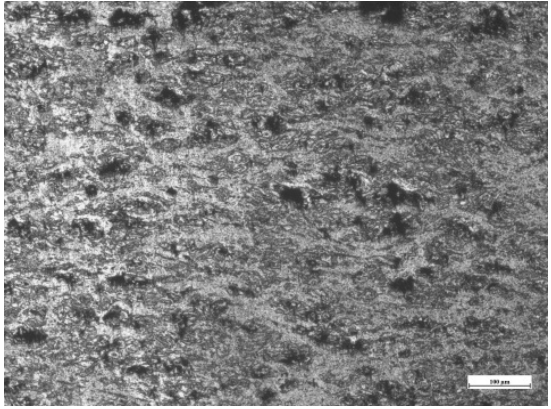

(a)

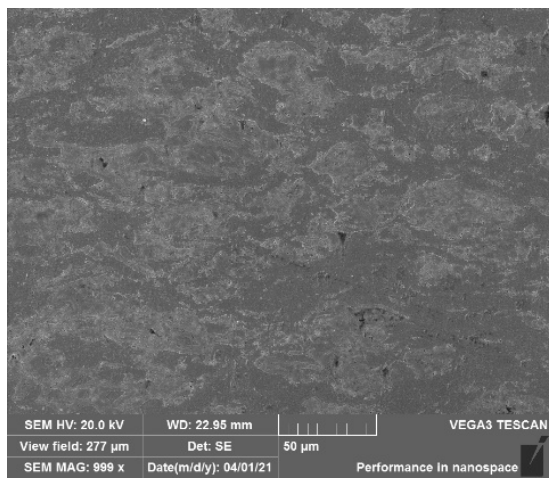

(d)

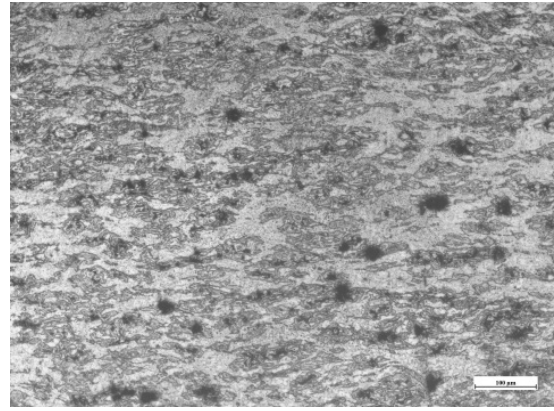

(b)

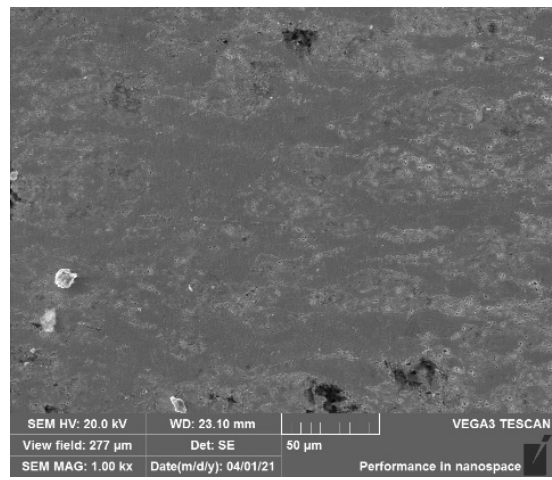

(e)

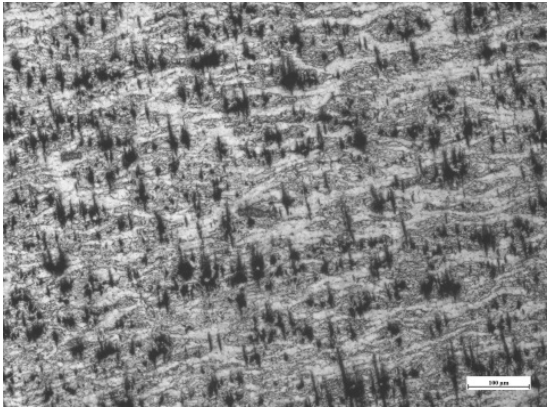

(c)

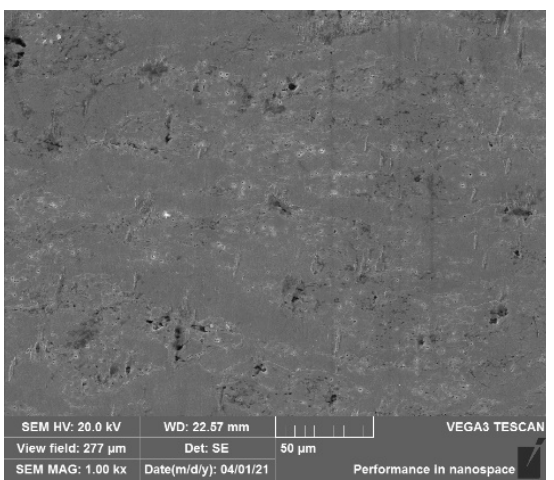

(f)

Figure 11. Microstructure of Zr-6Al-0.1B alloy at $0.1 \mathrm{~s}^{-1}$ : (a) OM image of $950{ }^{\circ} \mathrm{C}$; (b) OM image of $1050{ }^{\circ} \mathrm{C}$; (c) OM image of $1150{ }^{\circ} \mathrm{C}$; (d) SEM image of $950^{\circ} \mathrm{C}$; (e) SEM image of $1050{ }^{\circ} \mathrm{C}$; (f) SEM image of $1150^{\circ} \mathrm{C}$.

On the whole, the increase of deformation temperature contributes to grain refinement. However, when the temperature is too high, due to the decomposition of $\mathrm{Zr}_{3} \mathrm{Al}$ phase the deformation coordination of the material decreases. It will lead to the increase of the probability of the occurrence of defects, such as holes. Through an overall consideration, it is suggested that the deformation temperature should be higher than the phase transition temperature of $\alpha-\mathrm{Zr}$ to $\beta-\mathrm{Zr}\left(863^{\circ} \mathrm{C}\right)$, but lower than the decomposition temperature of $\mathrm{Zr}_{3} \mathrm{Al}\left(1019{ }^{\circ} \mathrm{C}\right) . \beta-\mathrm{Zr}$ and $\mathrm{Zr}_{3} \mathrm{Al}$ both have relatively good plasticity, which is beneficial to improve the uniformity of microstructure and reduce the possibility of defects [9-11].

\section{Conclusions}

(1) $\mathrm{Zr}-6 \mathrm{Al}-0.1 \mathrm{~B}$ alloy rich in $\mathrm{Zr}_{3} \mathrm{Al}$ phase can be prepared by vacuum hot-pressing sintering using the following parameters: powder composition is $93.9 \%$ pure zirconium powder (200 mesh) $+6 \%$ pure aluminum powder (200 mesh) $+0.1 \%$ aluminum boron alloy; powder mixing time is $30 \mathrm{~min}$ with ball mill ratio 1:1 at the mixing speed $100 \mathrm{r} / \mathrm{min}$; the hot-pressing sintering temperature is $950{ }^{\circ} \mathrm{C}$ with sintering pressure $40 \mathrm{MPa}$ and sintering time $5 \mathrm{~min}$. The density of the sintered $\mathrm{Zr}-6 \mathrm{Al}-0.1 \mathrm{~B}$ alloy is $5.85 \mathrm{~g} / \mathrm{cm}^{3}$, the compactness can reach $97.91 \%$, the hardness can reach $614.5 \mathrm{HV}$.

(2) The sintered $\mathrm{Zr}-6 \mathrm{Al}-0.1 \mathrm{~B}$ alloy belongs to the temperature and strain rate sensitive material. At the early stage of thermal deformation, the stress increases rapidly with the increase of strain under the influence of work hardening and then reaches the peak value. Under the softening effect of dynamic recovery and dynamic recrystallization, the stress decreases with the increase of strain. On the whole, the true stress-strain curve shifts to the high stress area with the increase of strain rate or the decrease of deformation temperature.

(3) The high deformation rate is conducive to improving the grain refinement of sintered $\mathrm{Zr}-6 \mathrm{Al}-0.1 \mathrm{~B}$ alloy, but a too high deformation rate will exceed the deformation capacity of the material, resulting in an increase in defects. The increase of deformation temperature contributes to grain refinement, but when the temperature is too high, due to 
the decomposition of $\mathrm{Zr}_{3} \mathrm{Al}$ phase, the deformation coordination of the material decreases, leading to the increase of the probability of the occurrence of defects.

Author Contributions: Conceptualization, H.Y. and S.Z.; methodology, J.L.; software, B.W.; validation, W.W., S.M. and J.L.; formal analysis, W.W.; investigation, W.W. and B.W.; resources, H.Y.; data curation, B.W.; writing-original draft preparation, W.W.; writing-review and editing, W.W.; visualization, H.Y.; supervision, S.Z.; project administration, S.Z.; funding acquisition, S.Z., W.W. and S.M. All authors have read and agreed to the published version of the manuscript.

Funding: Author Shuangjie Zhang acknowledges the support from the Key Research and Development Program of Hebei Province (Grant No. 19251019D). Author Wei Wang acknowledges the support from the Nature Science Foundation of Hebei Province (Grant No. E2021208025). Author Shibo Ma acknowledges the support from the High-level Talents Funding Project of Hebei Province (Grant No. A202101016).

Institutional Review Board Statement: Not applicable.

Informed Consent Statement: Not applicable.

Data Availability Statement: The data presented in this study are available on request from the corresponding author.

Conflicts of Interest: The authors declare no conflict of interest.

\section{References}

1. Xie, Y.; Yang, S.; Dai, S.; Lu, Z. Mechanical properties and strengthening mechanism of aluminum alloys containing zirconium. Chin. J. Nonferrous Met. 2003, 13, 1192-1195. (In Chinese)

2. Helmi Attia, M. On the fretting wear mechanism of Zr-alloys. Tribol. Int. 2006, 39, 1320-1326. [CrossRef]

3. Wei, K.; Qu, Y.; Li, J.; Chen, L.; Du, J.; Xue, W. Surface charge and corrosion behavior of plasma electrolytic oxidation film on $\mathrm{Zr}_{3} \mathrm{Al}$ based alloy. Surf. Coat. Tech. 2019, 357, 412-417. [CrossRef]

4. Fecht, H.J.; Han, G.; Fu, Z.; Johnson, W.L. Metastable phase formation in the Zr-Al binary system induced by mechanical alloying J. Appl. Phys. 1990, 67, 1744-1748. [CrossRef]

5. Ma, E.; Atzmon, M. Calorimetric evidence for polymorphous constraints on metastable Zr-Al phase formation by mechanical alloying. Phys. Rev. Lett. 1991, 67, 1126. [CrossRef] [PubMed]

6. Zhao, S.Z.; Li, J.H.; Liu, B.X. Local structure of the Zr-Al metallic glasses studied by proposed $n$-body potential through molecular dynamics simulation. J. Mater. Res. 2010, 25, 1679-1688. [CrossRef]

7. Du, J.; Wen, B.; Melnik, R.; Kawazoe, Y. Cluster characteristics and physical properties of binary Al-Zr intermetallic compounds from first principles studies. Comp. Mater. Sci. 2015, 103, 170-178. [CrossRef]

8. Mohammadi, A.; Enikeev, N.A.; Murashkin, M.Y.; Arita, M.; Edalati, K. Developing age-hardenable Al-Zr alloy by ultra-severe plastic deformation: Significance of supersaturation, segregation and precipitation on hardening and electrical conductivity. Acta Mater. 2021, 203, 116503. [CrossRef]

9. Jiang, X.J.; Zhang, Y.Y.; Li, C.L.; Liang, G.D.; Han, R.H.; Zhang, X.Y. Microstructure and mechanical properties of ZrAl binary alloys. J. Alloys Compd. 2019, 811, 152068. [CrossRef]

10. Li, J.; Mao, L.; Zhang, F.; Wang, Q.; Guo, D.; Ma, J.; Li, Q. Effect of Al content and annealing temperature on phase compositions and mechanical properties of ZrAl Alloys. Rare Metal Mat. Eng. 2014, 43, 2227-2231.

11. Li, J.H.; Gao, Y.; Liu, S.; Mao, L.; Zhang, F.C.; Li, Q. The effects of alloy composition and annealing time on microstructure and mechanical properties of $\mathrm{Zr}_{3} \mathrm{Al}$-based alloys. Mater. Res. Innov. 2015, 19, 55-58. [CrossRef]

12. Tewari, R.; Dey, G.K.; Banerjee, S.; Prabhu, N. Microstructural evolution in $\mathrm{Zr}_{3} \mathrm{Al}$-based alloys during various long-time annealing treatments. Metall. Mater. Trans. A 2006, 37, 49-58. [CrossRef]

13. Ren, Z.; Xue, Z.; Zhang, X.; Qin, J.; Ma, M.; Liu, R. Atomic diffusion mediated by vacancy defects in $\mathrm{L1}_{2}-\mathrm{Zr}_{3} \mathrm{Al}$ : A first-principles study. J. Alloys Compd. 2020, 824, 153223. [CrossRef]

14. Yuan, X.; Wei, D.; Cheng, Y.; Ji, G.; Zhang, Q.; Gong, Z. Pressure effects on elastic and thermodynamic properties of Zr $\mathrm{r}_{3} \mathrm{Al}$ intermetallic compound. Comp. Mater. Sci. 2012, 58, 125-130. [CrossRef]

15. Arıkan, N. The first-principles study on $\mathrm{Zr}_{3} \mathrm{Al}$ and $\mathrm{Sc}_{3} \mathrm{Al}$ in $\mathrm{L}_{2}$ structure. J. Phys. Chem. Solids 2013, 74, 794-798. [CrossRef]

16. Knipling, K.E.; Karnesky, R.A.; Lee, C.P.; Dunand, D.C.; Seidman, D.N. Precipitation evolution in Al-0.1Sc, Al-0.1Zr and Al-0.1Sc-0.1Zr (at.\%) alloys during isochronal aging. Acta Mater. 2010, 58, 5184-5195. [CrossRef]

17. Xu, J.; Freeman, A.J. Phase-stability and electronic-structure of $\mathrm{ScAl}_{3}$ and $\mathrm{ZrAl}_{3}$ and of Sc-stabilized cubic $\mathrm{ZrAl}_{3}$ precipitates. Phys. Rev. B 1990, 41, 12553-12561. [CrossRef]

18. Wang, J.; Zheng, W.; Xu, G.; Zeng, X.; Cui, Y. Thermodynamic assessment of the Ti-Al-Zr system and atomic mobility of its bcc phase. Calphad 2020, 70, 101801. [CrossRef] 
19. Mundhra, G.; Hariharan, V.S.; Murty, B.S. Design of a novel Al-Ti-Zr light-weight alloy: CALPHAD and experiments. J. Alloys Compd. 2020, 835, 155304. [CrossRef]

20. Sarkar, B.K.; Verma, A.S.; Deviprasadh, P.S. First-principles phase stability calculations of $\mathrm{Zr}_{3} \mathrm{Al}_{1-\mathrm{x}} \mathrm{Nb}_{\mathrm{x}}$ alloys with $\mathrm{L} 1_{2}$ and $\mathrm{DO}_{\mathrm{a}}$ Structures. In TMS 2015 144th Annual Meeting \& Exhibition; The Minerals, Metals \& Materials Society, Ed.; Springer: Berlin/Heidelberg, Germany, 2015; pp. 713-719.

21. Li, J.H.; Li, Q.; Zhang, F.C.; Liu, S.; Mao, L.; Hu, B.C.; Yang, Z.N. Effects boron on microstructure and mechanical properties of $\mathrm{Zr}_{3} \mathrm{Al}$-based alloys. Mater. Lett. 2015, 153, 70-72. [CrossRef]

22. Ivasishin, O.M. Production of titanium alloys and parts by the economical powder metallurgy method for large-scale industrial applications. Nauka I Innovatsii 2005, 2, 45-57.

23. Qiu, C.L.; Attallah, M.M.; Wu, X.H.; Andrews, P. Influence of hot isostatic pressing temperature on microstructure and tensile properties of a nickel-based superalloy powder. Mat. Sci. Eng. A 2013, 564, 176-185. [CrossRef]

24. Sreenu, B.; Sarkar, R.; Satheesh Kumar, S.S.; Chatterjee, S.; Appa Rao, G. Microstructure and mechanical behaviour of an advanced powder metallurgy nickel base superalloy processed through hot isostatic pressing route for aerospace applications. Mat. Sci. Eng. A 2020, 797, 140254. [CrossRef]

25. Jeevan, V.; Rao, C.S.P.; Selvaraj, N.; Bhaskar Rao, G. Fabrication and characterization of AA6082-ZTA composites by powder metallurgy process. Mater. Tod. Proc. 2018, 5, 254260. [CrossRef]

26. Kondoh, K.; Fukuo, M.; Kariya, S.; Shitara, K.; Li, S.; Alhazaa, A.; Umeda, J. Quantitative strengthening evaluation of powder metallurgy Ti-Zr binary alloys with high strength and ductility. J. Alloys Compd. 2021, 852, 156954. [CrossRef]

27. Tang, L.T.; Zhu, D.G.; Sun, Z.; Jiang, X.S.; Song, T.F.; Hu, C.F. Microstructure and mechanical properties of Al-Ti-Zr intermetallic compounds prepared by vacuum hot pressing. Vacuum 2018, 150, 166-172. [CrossRef]

28. Xu, W.; Lu, X.; Hayat, M.D.; Tian, J.; Huang, C.; Chen, M.; Qu, X.; Wen, C. Fabrication and properties of newly developed Ti35Zr28Nb scaffolds fabricated by powder metallurgy for bone-tissue engineering. J. Mater. Res. Technol. 2019, 8, 3696-3704. [CrossRef]

29. Ma, G.; Wang, D.; Liu, Z.; Bi, S.; Zan, Y.; Xiao, B.; Ma, Z. Effect of hot pressing temperature on microstructure and tensile properties of SiC/Al-Zn-Mg-Cu Composites. Acta Metall. Sin. 2019, 55, 1319-1328.

30. Huo, S.; Wang, Y.; Yao, M.; Chen, L.; Kong, Q.; Ouyang, J.; Fu, Y.; Zhou, Y. Reactive sintering behavior and enhanced densification of (Ti,Zr)B $\mathrm{B}_{2}-(\mathrm{Zr}, \mathrm{Ti}) \mathrm{C}$ composites. J. Eur. Ceram. Soc. 2020, 40, 4373-4380. [CrossRef]

31. Dekhtyar, A.I.; Bondarchuk, V.I.; Karasevska, O.P.; Oryshych, D.V.; Savvakin, D.G.; Skoryk, M.A. Microstructure change under hot deformation in zirconium alloys synthesized by powder metallurgy. Mater. Charact. 2019, 158, 109949. [CrossRef]

32. Lakshman, S.V.; Gibbins, J.D.; Wainwright, E.R.; Weihs, T.P. The effect of chemical composition and milling conditions on composite microstructure and ignition thresholds of Al-Zr ball milled powders. Powder Technol. 2019, 343, 87-94. [CrossRef]

33. Wainwright, E.R.; Weihs, T.P. Microstructure and ignition mechanisms of reactive aluminum-zirconium ball milled composite metal powders as a function of particle size. J. Mater. Sci. 2020, 55, 14243-14263. [CrossRef]

34. Alatalo, M.; Weinert, M.; Watson, R.E. Stability of Zr-Al alloys. Phys. Rev. B 1998, 57, R2009. [CrossRef]

35. Kim, Y.; Song, Y.; Lee, S.H.; Kwon, Y. Characterization of the hot deformation behavior and microstructural evolution of Ti-6Al-4V sintered preforms using materials modeling techniques. J. Alloys Compd. 2016, 676, 15-25. [CrossRef]

36. Li, X.; Liu, C.; Luo, K.; Ma, M.; Liu, R. Hot deformation behaviour of SiC/AA6061 composites prepared by spark plasma sintering. J. Mater. Sci. Technol. 2016, 32, 291-297. [CrossRef]

37. Sun, F.; Li, B.; Cai, C.; Cai, Q. Effects of TiN nanoparticles on hot deformation behavior of ultra-fine grained Al2024-TiN nanocomposites prepared by spark plasma sintering. Mech. Mater. 2019, 138, 103152. [CrossRef]

38. Emdadi, A.; Sizova, I.; Bambach, M.; Hecht, U. Hot deformation behavior of a spark plasma sintered Fe-25Al-1.5Ta alloy with strengthening Laves phase. Intermetallics 2019, 109, 123-134. [CrossRef]

39. Yang, F.; Zhang, D.; Gabbitas, B.; Lu, H.; Wang, C. Microstructural evolution during extrusion of a Ti/Al/Al35V65 (Ti-6Al-4V) powder compact and the mechanical properties of the extruded rod. Mat. Sci. Eng. A 2014, 598, 360-367. [CrossRef]

40. Yang, F.; Gabbitas, B. Feasibility of producing Ti-6Al-4V alloy for engineering application by powder compact extrusion of blended elemental powder mixtures. J. Alloys Compd. 2017, 695, 1455-1461. [CrossRef]

41. Singh, A.P.; Yang, F.; Torrens, R.; Gabbitas, B. Solution treatment of Ti-6Al-4V alloy produced by consolidating blended powder mixture using a powder compact extrusion route. Mat. Sci. Eng. A 2018, 712, 157-165. [CrossRef] 